\title{
Development of a Method for Obtaining a Wear-Resistant Coating for a Cutting Tool
}

\author{
A. E. Litvinov ${ }^{1, a^{*}}$, V. U. Buzko ${ }^{2, b}$ E. Yu. O. Balaev ${ }^{1, c}$ and A. I. Goryachko,d \\ ${ }^{1}$ Institute of Mechanical Engineering and Car Service, Kuban State Technological University, \\ Krasnodar, Russia \\ ${ }^{2}$ Kuban State University, Krasnodar, Russia \\ aartstyleone@mail.ru, bbuzkonmr@mail.ru, cbalaev1122@mail.ru, da_i_goryachko@mail.ru
}

\begin{abstract}
Keywords: High-Entropy Alloys, Mechanical Activation, Mechanical Alloying, Coatings, High-Velocity Oxygen-Fuel Spraying, Structure, Phase State
\end{abstract}

\begin{abstract}
The article presents a method for producing a nanostructured wear-resistant high-hard coating with high physicomechanical and strength characteristics, resistance to shock and vibration loads. The result is an increase in adhesion between the substrate and the coating, as well as an increase in microhardness. One of the common methods of metal cutting is band-cutting machines that use closed band saws as cutting tools. Since materials with high physicomechanical characteristics (hardness, strength, etc.) are increasingly being used in modern production, which significantly complicates the cutting process and makes increased demands on the cutting tool. To expand the range of processed materials for which the productive use of band-cutting machines is possible, it became necessary to create a band saw with higher cutting characteristics. At the same time, the specificity of the working conditions of the band saw shows that the blade should have such characteristics as increased vibration resistance, resistance to alternating and dynamic loads, and the cutting part of the saw should have increased resistance to shock, dynamic, alternating loads, have high hardness, as well as increased wear resistance.
\end{abstract}

\section{Introduction}

One of the common methods of metal cutting is band-cutting machines that use closed band saws as cutting tools. Since materials with high physicomechanical characteristics (hardness, strength, etc.) are increasingly being used in modern production, which significantly complicates the cutting process and makes increased demands on the cutting tool. To expand the range of processed materials for which the productive use of band-cutting machines is possible, it became necessary to create a band saw with higher cutting characteristics. At the same time, the specificity of the working conditions of the band saw shows that the blade should have such characteristics as increased vibration resistance, resistance to alternating and dynamic loads, and the cutting part of the saw should have increased resistance to shock, dynamic, alternating loads, have high hardness, as well as increased wear resistance. [1,2]

The idea of creating a layered composite is one of the right directions for solving this problem. So, the layered composite material proved to be workable under difficult loading conditions on other engineering products and firmly strengthened its position in the production, since with the correct analysis of the working conditions of the product, whether it be a part or a cutting tool, in particular a band saw blade, it can be found that this or that zone or layer can work on a specific type of loading. Therefore, it can be made of a material with characteristics that satisfy these load conditions. Thus, on the basis of the analysis of loading conditions during the operation of the band saw blade, the idea of bimetallic saw was proposed, which is the right direction to solve the 
problem, but the main disadvantage is the presence of a welded joint sensitive to vibration, dynamic and shock loads, and the difficulty of obtaining a defect-free welded joint seam. An alternative could be surface plasma alloying of the teeth of the band saw blade, which allows significantly changing the physicomechanical characteristics of the material of the cutting edge of the teeth (which will be the material of the whole band saw blade - spring-spring steel). At the same time, the output is a layered composite with high adhesion, comparable in value to metallurgical, since the band saw blade material is alloyed, which is also the base material, and with correctly selected modes it is possible to reduce the values of possible residual deformation as a result of heat treatment to zero.[1-4]

\section{Research materials and methods}

For the research, the following equipment was used: a JET band saw (testing the obtained saws under conditions close to factory conditions), a Falcon 500 micro hardness meter (micro hardness tests for preliminary analysis of wear resistance), an Instron 8801 testing machine (fatigue test), installation of a magnetron radio frequency spraying Q150T ES (coating process), scanning electron microscope "JEOL JSM - 7500F" (studying the microstructure of coatings), Bruker Vertex 70 FTIR IR spectrometer (for analyzing the composition of coatings).

\section{Discussion of the results}

To apply nanostructured and wear-resistant high-hard coatings by magnetron sputtering on the surface of cutting tools, a sequential technological cycle is used in the work, which includes: 1) Preliminary etching of the product surface with low-temperature argon plasma to improve the adhesion of the applied protective coating; 2) Application by the method of magnetron-plasma spraying of a nanostructured film of metal or alloy on the surface of the product; 3) Thermal oxidative phase-forming annealing for the appearance of nanoparticles of high-hard oxides of a cubic system (aluminum or chromium oxides) and nanoparticles of medium-hard oxides (oxides of titanium, niobium, vanadium), which also leads to an increase in the adhesion of the protective coating, an increase in hardness, wear resistance and fatigue strength due to the recrystallization process applied coating.

A method of obtaining a wear-resistant coating for a cutting tool, comprising applying a coating on the surface of a cutting tool based on an alloy of titanium, aluminum and niobium, while obtaining a coating on the surface of the cutting tool is carried out by magnetron-plasma spraying including preliminary plasma etching of the surface of the cutting tool in a vacuum chamber with accelerated ions at a pressure of 1-3 Pa, after which there is an ion-plasma spraying of the coating carried out at a pressure of 1-3 Pa, current 100-150 mA to obtain a coating of the composition TiAlVNbTiB2 in the following ratio, weight\%: Al 5.5-6.5; V 7-8; Nb 2-4 TiB2 1-2; Ti - the rest, and subsequent phase-forming thermal oxidative annealing at a temperature of $550-650{ }^{\circ} \mathrm{C}$ for 1 2 hours. [5]

Preliminary etching of the surface of the tool allows you to increase the adhesion strength between the coating and the cutting tool due to the microstructure of the surface of the cutting tool and allows you to easily clean the surface of the product from contaminants and grease residues. At the same time, ion-plasma etching (surface ablation of the material) occurs, which allows you to change the structural and mechanical properties of the product, increase the roughness, which will improve the adhesion between the surface of the metal of the cutting tool and the applied material. Plasma treatment can be applied to a wide range of types of cutting tools of any composition and complex geometric shapes. Ion-plasma etching can improve the physicomechanical properties of the resulting cutting tool. 
Using magnetron-plasma spraying, nanostructured metal thin-layer films of the desired chemical composition and thickness are applied with high adhesion, which is close in value to metallurgical. In the method for producing a coating, thermal cutting of the cutting tool does not occur, so that no residual stresses occur on the surface of the tool and along the product-coating interfaces. In turn, the resistance of the coated cutting tool to fatigue cracking increases. Also, ionplasma deposition occurring at room temperature provides a coating having a nanoscale structure in the size range of 5-15 $\mathrm{nm}$. Thin nanostructured coatings, with a certain shape (cubic and tetragonal syngonies) and the size of nanoparticles (belonging to the region of maximum realization of the Hall-Petch effect), show ultra-high hardness, high fatigue strength and increased wear resistance.

Obtaining on the surface of a cutting tool a coating based on titanium aluminum alloy can increase the heat resistance and heat resistance of the cutting edge, which allows for a long time to save the geometry of the cutting edge of the tool and, as a result, the cutting characteristics of the tool.

Alloying titanium-aluminum alloy with vanadium to $8 \%$ allows the crystal lattice of the TiAl alloy to be transferred from a tetragonal to cubic form, which in turn improves the plasticity of the resulting coating, thereby increasing the resistance of the coating to fatigue cracking. Also, the transfer from a tetragonal to a cubic lattice allows TiAl alloys to increase the microhardness of the coating, which also increases the wear resistance of the tool[6-8].

Alloying a titanium-aluminum alloy with niobium leads to an increase in the thermodynamic activity of $\mathrm{Al}$ compared to $\mathrm{Ti}$, thereby contributing to the formation of a stable protective $\mathrm{Al} 2 \mathrm{O} 3$ layer on the coating surface, while the $\mathrm{A} 12 \mathrm{O} 3$ oxide film has a high microhardness and a dense structure that blocks further oxidation of the coating, including titanium, contained in the coating, also the $\mathrm{A} 12 \mathrm{O} 3$ oxide film increases the corrosion resistance and wear resistance of the coating.

The addition of a small amount of titanium diboride TiB2 to the coating composition, which is a strengthening dispersion phase that is in equilibrium with an alloy of titanium and aluminum (titanium aluminum) with good physicochemical and mechanical compatibility, can increase the strength characteristics of the coating and microhardness and maintain ductility and viscosity, increase heat resistance and heat resistance, due to the blocking of grain growth of the structure with increasing temperature, which always accompanies the process of metal cutting.

Thermal oxidative phase-forming annealing makes it possible to create a surface layer of highhardness, highly heat-resistant nanoparticles of cubic phase oxides on the surface of a metal adhesive film of a tool, which results in high-hardness coatings with high wear resistance and considerable fatigue resistance.

Obtaining a wear-resistant coating for a cutting tool, as follows, at the first stage, the product surface is pre-etched with low-temperature argon plasma to improve the adhesion of the protective coating in the vacuum chamber by accelerated ions at a pressure of 1-3 $\mathrm{Pa}$, after which a nanostructured film is applied by magnetron-plasma spraying from TiAlVNbTiB2 alloy in the following ratio, $\mathrm{wt} \%$ : Al 5.5-6.5; $\mathrm{V} 7-8$; $\mathrm{Nb}$ 2-4; TiB2 1-2; Ti - the rest, by transferring from the target surface a similar composition to the coating onto the surface of the cutting tool, after which thermal oxidative phase-forming annealing is carried out at a temperature of $550-650{ }^{\circ} \mathrm{C}$ for $1-2$ hours for the appearance of nanoparticles of high-hardness cubic oxide oxides (aluminum oxides), also leading to an increase in the adhesion of the protective coating, an increase in hardness, wear resistance, corrosion resistance and fatigue strength due to the process of recrystallization of the applied coating. 
Example 1. Obtaining a wear-resistant coating for a cutting tool, as follows, at the first stage, the surface of the product is pre-etched with low-temperature argon plasma to improve the adhesion of the applied protective coating in the vacuum chamber by accelerated ions at a pressure of $3 \mathrm{~Pa}$, after which a nanostructured TiAlVNbTiB2 alloy film is applied by magnetron-plasma spraying in the following ratio, weight $\%$ : Al 5.5; V 7; $\mathrm{Nb} 2$; TiB2 1; Ti - the rest, by transferring from the target surface a similar composition to the coating onto the surface of the cutting tool, after which thermal oxidative phase-forming annealing is carried out at a temperature of $550^{\circ} \mathrm{C}$ for 1 hour for the appearance of nanoparticles of high-hardness cubic oxide oxides (aluminum oxides), which also leads to an increase adhesion of the protective coating, an increase in hardness, wear resistance, corrosion resistance and fatigue strength due to the process of recrystallization of the applied coating

Example 2. Obtaining a wear-resistant coating for a cutting tool, as follows, at the first stage, the surface of the product is pre-etched with low-temperature argon plasma to improve the adhesion of the protective coating in the vacuum chamber by accelerated ions at a pressure of 2 $\mathrm{Pa}$, after which a nanostructured TiAlVNbTiB2 alloy film is applied by magnetron-plasma spraying in the following ratio, weight $\%: \mathrm{Al} 6 ; \mathrm{V} \mathrm{7.5;} \mathrm{Nb} 3 ; \mathrm{TiB} 2$ 1.5; Ti - the rest, by transferring from the target surface a similar composition to the coating onto the surface of the cutting tool, after which thermal oxidative phase-forming annealing is carried out at a temperature of $600{ }^{\circ} \mathrm{C}$ for 1.5 hours for the appearance of nanoparticles of high-hardness cubic oxide oxides (aluminum oxides), which also to increase the adhesion of the protective coating, increase hardness, wear resistance, corrosion resistance and fatigue strength due to the process of recrystallization of the applied coating

Example 3. Obtaining a wear-resistant coating for a cutting tool, as follows, at the first stage, the product surface is pre-etched with low-temperature argon plasma to improve the adhesion of the protective coating in the vacuum chamber by accelerated ions at a pressure of $1 \mathrm{~Pa}$, after which a nanostructured TiAlVNbA12O3 alloy film is applied by magnetron-plasma spraying in the following ratio, weight $\%$ : $\mathrm{Al} 6.5 ; \mathrm{V} 8 ; \mathrm{Nb} 4 ; \mathrm{TiB} 2$ 2; $\mathrm{Ti}$ - the rest, by transferring from the target surface a similar composition to the coating onto the surface of the cutting tool, then conduct thermal oxidative phase-forming annealing at $650^{\circ} \mathrm{C}$ for 2 hours for the appearance of nanoparticles of high-hardness cubic oxide oxides (aluminum oxides), which also leads to an increase adhesion of the protective coating, an increase in hardness, wear resistance, corrosion resistance and fatigue strength due to the process of recrystallization of the applied coating (table 1)

Table 1. Test results.

\begin{tabular}{|c|c|c|c|}
\hline \multicolumn{2}{|c|}{ Material } & $\begin{array}{c}\text { The processing } \\
\text { resistance of } \\
\text { 30HGSA, min. }\end{array}$ & $\begin{array}{c}\text { Microhardness, } \\
\text { GPa }\end{array}$ \\
\hline \multirow{3}{*}{ TiAIVNbTiB2 } & Example 1 & $82-84$ & 47,3 \\
\cline { 2 - 4 } & Example 2 & $85-87$ & 47,8 \\
\cline { 2 - 4 } & Example 3 & $88-90$ & 49,2 \\
\hline \multicolumn{2}{|c|}{ Prototype } & 81 & 46,7 \\
\hline
\end{tabular}


The microstructure of the obtained coatings (Figure 1) was studied using a JEOL JSM7500F scanning electron microscope. The microstructure of the obtained coatings on the saw teeth is shown in Figure 1.

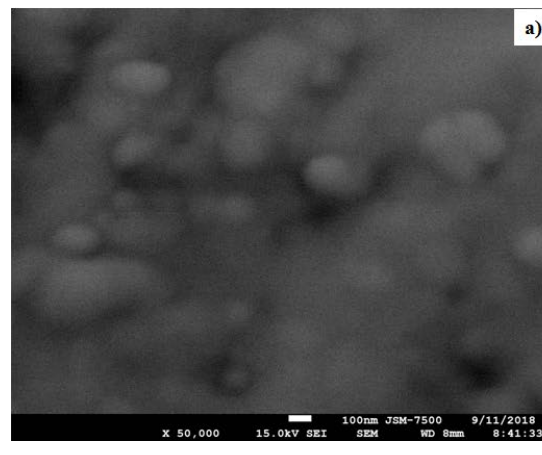

a a)

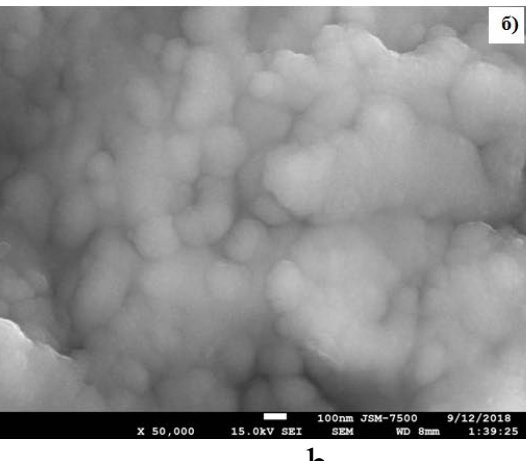

$\mathrm{b}$

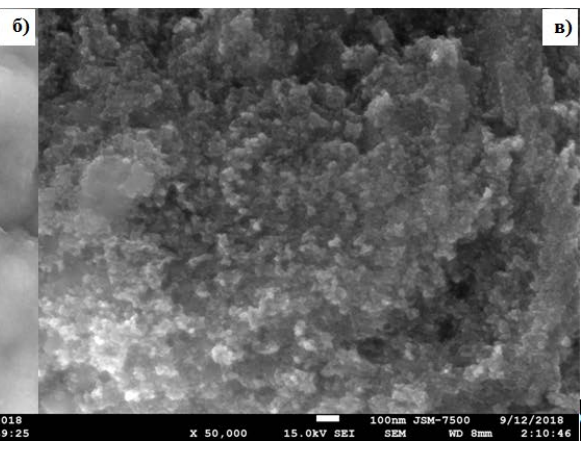

$\mathrm{c}$

Fig. 1. Microstructure of the obtained coatings $a$-nichrome Kh15N60; $b$ - Ti6Al4V alloy; cthermally oxidized aluminum $\left(\mathrm{Al}_{2} \mathrm{O}_{3}\right)$.

Analysis of the data presented in the table allows us to conclude that the cutting tool with a wear-resistant coating obtained by the present method are characterized by higher physicomechanical characteristics compared to inserts made by known methods. Thus, the combination of the claimed features allows to achieve the technical result.[9-12]

\section{Conclusions}

As a result of the research, a method for producing a wear-resistant coating for a cutting tool was developed, including applying a coating on the surface of a cutting tool based on an alloy of titanium, aluminum and niobium, characterized in that the coating on the surface of the cutting tool is carried out by magnetron-plasma spraying including preliminary plasma etching of the surface cutting tool in a vacuum chamber with accelerated ions at a pressure of 1-3 Pa, after which ion-plasma variable coating spraying carried out at a pressure of 1-3 Pa, a current of 100-150 mA to obtain a coating of the composition TiAlVNbTiB2 in the following ratio, weight $\%$ : $\mathrm{Al}$ 5.5-6.5; $\mathrm{V}$ 7-8; $\mathrm{Nb} 2-4 \mathrm{TiB} 2$ 1-2; Ti - the rest, and subsequent phase-forming thermal oxidative annealing at a temperature of $550-650^{\circ} \mathrm{C}$ for $1-2$ hours.[13-15]

\section{Acknowledgment}

This work was supported by a grant from the President of the Russian Federation (contract No.SP399.2019.1)

\section{References}

[1] S.V. Kiselev, A.V. Blakhin, A.F. Dulevich, "Band saws with high durability". Bulletin of BSTU. Vol 4, pp. 24-27, April 2007.

[2] A.E. Litvinov, "Improving tool life and machining precision in band saws". Russian Engineering Research.. Vol 36, pp. 760-761, 2016. https://doi.org/10.3103/S1068798X16090124

[3] Z.M. Blednova, P.O. Rusinov, E.U. Balaev, "Quantification of hereditary regularities of surface layer formation and transformation made of multicomponent shape memory materials in a high-energy impact" Materials Today: Proceedings . p. 4652-4657. 2017.

https://doi.org/10.1016/j.matpr.2017.04.046 
[4] L.X. Baldaev, V. Borisov, Gas thermal spraying. Textbook. 2007. p. 344.

[5] A. Hasui, O. Morigaki, Surfacing and spraying. Mechanical. Moskow, 1985 p. 240

[6] G.P. Laskin, A.P. Kuznechov, "Simulation of ion-plasma doping process". Bulletin of TumSU Vol 6, p 64-67, 2010

[7] V.A. Putilin, A.V. Kamashev, A.V. Putilin, "Alloyng of surface of metals under application of short palse laser” Mechanical engineering 2016. p. 344.

[8] M.K. Gusejnov, M.K. Kurbanov, B.A. Bilalov, G.K. Safaraliev, "Magnetron deposition of thin films of solid solution (SiC)1-x(AIN)x." Physics and technology of semiconductors. Vol 44, p. 841-844, 2010. https://doi.org/10.1134/S1063782610060217

[9] E.V. Rublevskaja, P.A. Komarova., A.V. Shcherbakova, T.D. Husnutdinov, E.V. Ramenskaja, "Analysis of parameters of cutting process by band saws" Actual problems of aviation and cosmonautics Vol 1, p.35-36, 2017

[10] V.P. Astahkov, Tribology of metal cutting p. 419, 2016

[11]L. Gan, R.D. Gomez , A. Castillo , P.J. Chen, C.J. Powell , W.F. Egelhoff Jr. Ultra-thin aluminum oxide as a thermal oxidation barrier on metal films. Thin Solid Films 415 (2002), pp. 219-223. https://doi.org/10.1016/S0040-6090(02)00622-3

[12] Pouilleau J, Devilliers D, Garrido F, et al. Structure and composition of passive titanium oxide films, Mater Sci Eng B. 1997; 47, pp. 235-243. https://doi.org/10.1016/S09215107(97)00043-3

[13] Dorian A. H. Hanaor \& Charles C. Sorrell. Review of the anatase to rutile phase transformation, Journal of Materials Science volume 46, pp. 855-874 (2011).

https://doi.org/10.1007/s10853-010-5113-0

[14] C. A. Vasantha Kumar, J. S. Rajadurai. Influence of rutile (TiO2) content on wear and microhardness characteristics of aluminium-based hybrid composites synthesized by powder metallurgy, Transactions of Nonferrous Metals Society of China, 2016, Volume 26, Issue 1, pp. 63-73. https://doi.org/10.1016/S1003-6326(16)64089-X

[15] JiaqinLiao, Rou Tan, Zhixiang Kuang, Chunyu Cui, Zengxi Wei, Xiaolan Deng, Zhanheng Yan, Yuezhan Feng, Fang Li, Caiyun Wang, Jianmin Ma. Controlling the morphology, size and phase of Nb2O5 crystals for high electrochemical performance, Chinese Chemical Letters, 2018, Volume 29, Issue 12, pp. 1785-1790. https://doi.org/10.1016/j.cclet.2018.11.018 